\title{
Ostrom, the commons, and the anthropology of "earthlings" and their atmosphere
}

\author{
Dan Rabinowitz
}

Elinor Ostrom, joint winner (with Oliver Williamson) of the 2009 Nobel prize in economic sciences, was quickly recognized by anthropologists as an honorary member of the tribe, and as someone whose achievements are a tribute to the discipline (see Baumard 2009; Wutich and Smth 2009). A political scientist by training, Ostrom was not formally trained as an anthropologist or an ethnographer. This notwithstanding, her commitment to empirical field research and her preoccupation since the early 1970s with the role of collective action, trust, and cooperation in arrangements designed to enhance the management of common pool resources (CPRs) repeatedly directed her toward populations (indigenous groups at the margins of states) and issues (institutions designed and operated at the community level) usually associated with anthropology.

CPRs are natural or man-made systems with three main characteristics. First, the system must have a valuable resource perceived to belong collectively to a well-defined community. Second, the limited size of the resource and the types of yields it offers allow the community to effectively exclude non-members from accessing it. This sets it apart from open access resources such as oceans, the atmosphere, and mathematical equations that are universally available to all (see Rose 2003). Third, being subtractable, CPRs are inherently vulnerable to congestion and overexploitation by the members of the community who are entitled to use it. Consisting of what economists label "core volume" (or "stock variable") and "fringe units" (or "flow variables"), CPRs presents a complex challenge. The extraction of flow variables must take place without depleting stocks, and distribution between members must take place without violating the prevailing social fabric and its institutional realities. Examples of natural CPRs include huntable game or mineral deposits situated in a territory associated with a given group. Examples of manmade CPRs include village wells and cisterns, pasture plots set aside for seasonal use, or preconstructed communal hunting devices like large scale traps or chase-lines.

Sustainable management of flow units such as the quantity and types of animals hunted, or the amount of water drawn from communally owned irrigation systems requires intimate knowledge of the resource, its depletion and replenishment cycles. Distributing those flow units between members of the community requires a separate set of skills and sensibilities, including the ability to work within existing institutional structures and the capacity to adapt to them and to expand them further. Miscalculations on either front, whether fueled by greed or ignorance, could be detrimental to the longterm ability of the resource and the community depending on it to survive.

The complexity of these tasks was succinctly indicated in Hardin's 1968 seminal article on 
the tragedy of the commons. Ostrom, who had always been preoccupied with paradoxes and contradictions surrounding humans and their choices, with a strong commitment to rational choice theory, became a major player in the debate that followed Hardin's work (see Ostrom et al. 1999), and a leading thinker on what has since been known as institutional behavior. Her Institutional Analysis and Development framework was particularly pertinent to public choice theory, which tends to view politicians and government officials as self-interested agents and to analyze their performance as attempts at maximizing personal utility. The balance politicians tend to strike between personal gain and communal interests is in fact akin to the juggling act that individuals involved in CPRs must perform. In both cases agents walk the fine line between immediate individual benefit and longterm communal welfare. This perspective, and the obvious parallels it has with game theory, social choice theory, and decision theory, has informed Ostrom's extensive work on organizational theory and public administration.

Ostrom's work on CPRs focused on communities' interfaces with their ecosystems and the internal dynamics that emerge as they endeavor to secure long-term sustainable yields. This preoccupation, combined with Ostrom's commitment to positivism and empirical work, drew her and her students to study pasture management in Africa, irrigation systems in Nepal, fishermen in Maine, and more (see Acheson 1989; McKean 1992; Singleton and Taylor 1992).

Governing the commons (1990), the volume that summarizes the first decade of Ostrom's empirical work on CPRs, provides a basic list of institutional characteristics that enhance successful management of commonly held resources. The list includes clearly defined system boundaries that allow the effective exclusion of non-members; rules governing resource usage that fit local conditions; wide participation of local stakeholders in the design and implementation of rules and decisions governing the system; transparent, effective, and accountable monitoring of rules and their compliance; flex- ible and gradual sanctions for violators of accepted rules; easily accessible mechanisms of arbitration and conflict resolution; recognition on the part of state authorities of the local community and its jurisdiction over its CPR; and, when the system in question is large-scale and complex, a hierarchical organization of local CPRs as nested in a multi-layered set of enterprises. These traits, Ostrom suggests, should be enhanced and cultivated when systems with CPR potential are singled out for further development and funding.

Significantly, Ostrom's CPR research, while highlighting local successes, was empirical and level headed enough to avoid romanticized idealization of indigenous ingenuity. Recognizing that small-scale communal management techniques are not immune to failure, and that attempts at CPR management have known to fail and trigger societal collapse, she and her students did well to avoid putting CPR on a pedestal. Pleasantly surprising as some of her findings in this realm have been, she never claimed that indigenous CPR management patterns is the one and only magic formula for sustainable ecosystem management.

With time, Ostrom's Bloomington-based Institutional Analysis and Development Research Program became one of the pillars of the New Institutional Theory movement. Combining a rigorous interdisciplinary theoretical approach with hard-nosed empiricism, the program had a clear agenda: to reintroduce the original liberal thought of Locke and Adam Smith, Montesquieu, Hamilton and Hume, Madison and de Tocqueville into the rapidly changing sociopolitical context of the twenty-first century. In 2006 Ostrom officially joined Arizona State University's School of Human Evolution and Social Change, and became the founding director of the Center for the Study of Institutional Diversity. There, faculty and students, many of them anthropologists, "draw from a wide range of methods, including ethnography, experiments, network analysis, mathematical modeling and archival research, to understand how institutions emerge, evolve and endure. Most are working 
on small scale social systems and many are working on problems of common pool resources" (Wutich and Smith 2009: 24).

My analytical concern here is not with the extent to which Ostrom and her project could or should be labeled "anthropological" or even "ethnographic." These distinctions, which may be pertinent to debates on inter-disciplinary boundaries, hierarchy, and prestige, are less significant than the debate concerning Ostrom's awkward relationship with history and power. I argue that her commitment to rational choice theory, her somewhat disjointed use of ethnography, and her imperfect theoretical positioning of scale, all of which have served her well in the development of fresh ideas regarding CPRs, are precisely those that limit the applicability of her ideas to other, more complex, politicized contexts. These tendencies constrain the potential of institutional analysis to enhance contemporary efforts to theorize the most important segment of our global commons, namely the atmosphere.

Ostrom originally became known for her interesting attempt to break the deadlock implied by Gareth Hardin's brilliant essay on the commons (Hardin 1968). Hardin's view of the commons as an inherently unstable-hence tragic-situation is inextricably linked to his rigid belief in humans' propensity for rational choice. Each member of the community, when faced with a common resource available for exploitation, will seek to do what he or she feels they are legitimately entitled to do: maximize personal gain by exploiting the resource as intensively as possible. When many individual members have made that choice for long enough, an inevitable moment comes when the resource is depleted to the point of collapse. And it is at that moment that everyone concerned, including those who used the resource responsibly and frugally, suffers existential crisis. Hardin's practical conclusion was that what ensues is a simple deadlock. The common resources will survive either by being subject to a draconian regulatory system operated by an almighty state, which he rightly claims is hardly practical; or by privatization of the commons- that is, by carving it into individually owned segments.
Ostrom is not in dispute with Hardin's belief in rational choice. What she seeks to show is that terminating the commons is not the only option. People, she argues correctly, sometimes do the right thing (consume common resources carefully and sustainably) even on the commons. And they do it best when they have an institutional arrangement that convinces them that enhancing the general good serves everybody's personal interest too. This step away from Hardin and toward Durkheim is interesting, but it does not go far enough. It does not open enough space for another option-that of people doing the right thing on the strength of solidarity, which in the final analysis is inexplicable in terms of rationality alone. Moreover, the role that power gradients, dependency, personal, and familial histories and so on play in shaping people's actions vis-à-vis the riddle of the commons is sidelined in much of Ostrom's work.

This is related to my second point-Ostrom's fragmentary use of ethnographic evidence. Generally aware of social and cultural factors, her work often seems to skim the surface of observable social and cultural data in a linear, mono-dimensional fashion. Unlike holistic ethnographic projects, in Ostrom's work the search seems to be for specific types of findings-signs of an institutional reality that fosters an effective CPR regime. This tendency to look only at what is under the spotlight does not necessarily mean that the results are false. They do suggest however that certain types of data are privileged, and that alternative explanations of the end result (sustainable use of CPR) might be overlooked.

The commitment to a-political rational choice and the rather flat ethnographic viewpoint that characterize institutional analysis could partially explain an interesting phenomenon: CPR analysis has been most promising for better understanding successes on small-scale, local commons. One in fact suspects that Ostrom's remarkable success in positioning CPR systems as effective alternatives to the neoliberal view that sees privatization as the only avenue to costeffective and sustainable resource husbandry was a major reason behind the decision to award 
her the Nobel. Yet when one looks at the contribution of institutional analysis of CPR systems to contemporary attempts to theorize the global commons, and in particular the atmosphere, the results are disappointing.

The gap, it must be said, is not necessarily an indication of the deficiencies of institutional analysis. It has more to do with the immense complexities associated with the global commons.

The diagnostic science and prognostic trajectories associated with the physical aspects of what I call the post normal climate condition (Rabinowitz 2009) are robust, not least through the sustained effort on the part of the UN's Intergovernmental Panel on Climate Change (IPCC 2007). It is the social context of the crisis that still begs for more effective theoretical analysis.

A better understanding of the social context of climate change requires new ways to analyze the macro-interface between humanity and the biosphere. Modernity almost convinced us that nature, and human vulnerability toward it, are quaint remnants of a pre-modern past. Now, as nature seems to be returning with a vengeance, if we insist on clinging to "the social" as an isolated category, in and of itself, detached from other planetary entities, we do so at our peril. Instead we should start tracing social relationships, economic interdependencies, and political assemblages all the way to their point of impact with the biosphere and the life supporting systems it provides.

Attempts to grasp the interface between humanity and the natural world are not new to the social sciences. Many of them, including Ostrom's contributions, are preoccupied with specific populations and their interfaces with their immediate local environments. What seems to be lacking are means for conceptualizing complex biospheric systems such as the atmospherethe ultimate Lefebvrian space-as a socially constructed, politicized place.

The atmosphere, by definition, is an open access, universal commons. The resources that it offers are diverse. When it comes to climate change, however, it is the atmosphere's capacity as sink-a depository for pollutants emitted as a side effect of various industrial processesthat is most relevant. Oblivious to the limits of the atmosphere's capacity to absorb $\mathrm{CO}_{2}$ and other greenhouse gases, humans have always treated the "great aerial ocean" as an unbounded sink, an endless frontier. Now, as the amounts of $\mathrm{CO}_{2}$ deposited in it are intensifying the greenhouse effect, changing the planet's heat balance, the need to better understand the atmosphere and to politicize its history and future becomes acute.

Breathing is probably the most immediate and frequent link we have to the biosphere. Conceptually, however, it remains abstract. The physical connections that shape it are too complicated to grasp. Their traction on social constructions of reality is too abstract to communicate. A space taken for granted, the atmosphere remains socially fragmented, hence difficult to signify and be imbued with meaning.

At least two obstacles are in the way of atmospheric social science. One is that we undertake it under pressure, during an impending climate crisis - a syndrome whereby the need to intervene might get the better of careful theoretical analysis. The other is that three decades of efforts to gain theoretical insight into the abstract syndrome we call globalization produced unsatisfactory results. Latour's (2007) exasperated exclamation that "we have no globe to work with" prompted an attempt based on his earlier work concerning science and modernity (1993) to establish "radical empiricism" as a means to expand the restricted modernistic notion of the social. Corresponding with Lovelock's (2006) The revenge of Gaia he proposes "earthlings" - a term consciously borrowed from science fiction - as a generic term for humans, which underscores our species' tendency to assault the planet. What I find useful in this science fiction trope is the implicit suggestion that humanity is not necessarily tantamount to modernist definitions of the social, which so heavily depend on the dichotomy with the natural world. "Earthlings" could well imply "things" (Appadurai 1986) with social life. Naming humans "earthlings" suggests our species is not the only one defining what the social is. Conse- 
quently, humans are not totally social, or no longer social, and perhaps have never been as truly social as they tend to believe.

Ostrom's work, like that of other institutional analysts, is admirably effective in shedding light on the dynamics governing the interface between local groups and their immediate commons. But when the scales and levels of complexity are altered, we are left with a restrictive definition of the social that fails to make the leap from Ostrom's concrete notion of the local commons to the breathtaking diversity and inter-connectedness of the atmosphere as sink and of climate as a global system.

Dan Rabinowitz is a socio-cultural anthropologist affiliated with the departments of sociology and anthropology at Tel-Aviv University and at Central European University. His recent books include Coffins on our shoulders (with Khawla Abu-Baker, 2005), Mixed towns, trapped minorities (co-editor, 2007), and Here it comes: How do we survive climate change (2009, in Hebrew). E-mail: msdan@post.tau.ac.il.

\section{References}

Acheson, James M. 1989. Economic anthropology and the management of common property resources. In Economic Anthropology, ed. S. Plattner, 351-78. Palo Alto, CA: Stanford University Press. Appadurai, Arjun. 1986. The social life of things: Commodities in cultural perspective. Cambridge: Cambridge University Press.

Baumard, Nicolas. 2009. Elinor Ostrom: Nobel Prize in Anthropology! International Cognition and Culture Institute website, October 12. http:// www.cognitionandculture.net/index.php? option=com_content\&view=article\&id=526: elinor-ostrom-nobel-prize-in-anthropology2009\&catid=37:nicolas\&Itemid $=34$ (accessed 28 February 2010).

Hardin, G. 1968. The tragedy of the commons. Science 162: 1243-48.

IPCC. 2007. Climate Change 2007: The physical science basis. Working Group 1 contribution to the fourth assessment report of the IPCC corporate author intergovernmental panel on climate change. http://ipcc-wg1.ucar.edu/wg1/wg1report.html. (accessed 11 January 2010).

Latour, Bruno. 1993. We have never been modern. Cambridge, MA: Harvard University Press. . 2007. A plea for earthly sciences. Keynote lecture for the annual meeting of the British Sociological. Association, East London, April.

Lovelock, James. 2006. The revenge of Gaia: Why the earth is fighting back - and how we can still save humanity. London: Allen Lane.

McKean, Margaret. 1992. Success on the commons: A comparative examination of institutions for common property resource management. Journal of Theoretical Politics 4 (3): 247-81.

Ostrom, Elinor. 1990. Governing the commons: The evolution of institutions for collective action. Cambridge: Cambridge University Press.

Ostrom, Elinor et al. 1999. Revisiting the commons: Local lessons, global challenges. Science 284: 278-82.

Rabinowitz, Dan. 2009. Here it comes: How do we survive climate change? Tel-Aviv: Hakibbutz Hameukhad (in Hebrew).

Rose, Carol. 2003. Romans, roads and romantic creators: Traditions of public property in the information age. Law and Contemporary Problems, Winter/Spring: 89-110.

Singleton, Sara, and Michael Taylor. 1992. Common property, collective action and community. Journal of Theoretical Politics 4 (3): 309-24.

Wutich, Amber, and Michael Smith. 2009. Anthropologists cheer Ostrom's nobel. Anthropology News (December): 24. 